\title{
WADAH REKREASI BERBASIS OLAHRAGA SEBAGAI RUANG KETIGA DI TEBET TIMUR :
} RE- SPOT, TEBET

\author{
Almira Livia Putri Laisa ${ }^{1)}$, Maria Veronica Gandha ${ }^{2)}$ \\ 1)Program Studi S1 Arsitektur, Fakultas Teknik, Universitas Tarumanagara, livia_almira@yahoo.co.id \\ 2)Program Studi S1 Arsitektur, Fakultas Teknik, Universitas Tarumanagara, mariag@ft.untar.ac.id
}

\begin{abstract}
Abstrak
Sejak tahun 2000-an, Tebet menjadi salah satu tempat nongkrong anak muda di Jakarta. Hingga saat ini Tebet semakin berkembang dengan dipenuhi dengan gerai distro dan cafécafé maupun restoran. Kawasan ini berpotensi sebagai Third Places bagi warga Tebet. Akan tetapi, dengan kurangnya sarana hiburan/rekreasi di Tebet, mampu mengurangi citra dari kawasan Tebet itu sendiri, karena menyebabkan pergerakan pengunjung menjadi semakin cepat. Re-Spot, Tebet merupakan salah satu pilihan masyarakat untuk dijadikan tempat nongkrong yang bersifat netral dengan adanya injection program baru di dalamnya yaitu Sport as Entertainment, dimana kegiatan entertainment disini merupakan bagian dari olahraga yang mempertimbangkan aspek kenyamanan pengguna dengan memanfaatkan potensi lingkungan setempat secara optimal. Dengan menggunakan injection program baru yang menyesuaikan minat dari anak muda di Tebet yang kemudian dielaborasikan dengan konsep Design By Sport Movement pada sirkulasi bangunan untuk menghasilkan sirkulasi yang merupakan bagian dari gerakan olahraga. Sehingga Re-Spot mampu menjadi inovasi baru bagi lingkungan Tebet Timur, dan juga menjadi ruang publik yang dapat menambah nilai bagi kegiatan yang sudah ada lingkungan Tebet Timur itu sendiri. Dengan membandingkan indicator berdasarkan teori mengenai ruang ketiga yang dipakai.
\end{abstract}

\section{Kata Kunci: Nongkrong; Olahraga Sebagai Sarana Hiburan; Ruang Ketiga}

\begin{abstract}
Since the 2000s, Tebet has been a gathering place for youngsters in Jakarta. Presently, Tebet continues to grow with shops, cafés, and restaurants. This area has the potential to become the Third Place for Tebet residents. However, with the lack of entertainment/recreation facilities in Tebet, it is able to diminish the concept of the Tebet area itself, because it creates moves of the visitors to become faster. Re-Spot, Tebet is one of the people's choices to be used as a neutral hang out space with a new injection program in it, namely Sport as Entertainment, where entertainment activities here are part of sports that consider aspects of user comfort by optimizing the potential of the local environment. By using a new injection program that fits the interests of youngsters in Tebet which is then elaborated with the concept of the Design by sports Movement in building circulation to create circulation which is part of the sports movement. Thus, Re-Spot will be an innovation for the Tebet Timur environment, and public space that can append a value to the activities that already exist in the Tebet Timur environment itself. By comparing indicators based on theories about the third space used
\end{abstract}

\section{Keywords: Hang out; Sports; Sports as Entertainment; Third Place}




\section{PENDAHULUAN}

\section{Latar Belakang Proyek}

Manusia merupakan makhluk social (sosial) yang berasal dari kata latin "socius" yang berarti kawan, sehingga sosial dapat dikatakan sebagai kemasyarakatan atau dalam makna sempit adalah mendahulukan kepentingan bersama atau masyarakat (Purwantiasning, 2017). Sehingga dari arti tersebut, manusia merupakan makhluk sosial yang selalu membutuhkan keberadaan manusia lain atau tidak dapat hidup sendiri. Kebutuhan bersosialisasi antar manusia pun beragam, dalam konteks ini, terdapat salah satu Kawasan di Jakarta yang terkenal dengan kegiatan bersosialisasi yang cukup tinggi. Tebet, merupakan salah satu nama Kecamatan yang terletak di DKI Jakarta tepatnya di Kota Administrasi Jakarta Selatan. Kecamatan ini memiliki luas wilayah $9.53 \mathrm{~km}^{2}$, yang terdiri atas 7 Kelurahan: Tebet Barat, Tebet Timur, Kebon Baru, Bukit Duri, Manggarai, Manggarai Selatan Dan Menteng Dalam terdapat satu Kelurahan yang sangat terkenal yaitu Tebet Timur daerah ini banyak digemari pemuda Jakarta untuk berbelanja dan dijadikan tempat berkumpul atau "nongkrong" sejak awal tahun 2000-an. Sehingga banyak terdapat café-café dan kios-kios pakaian berkembang disini. Sehingga Kawasan ini berpotensi sebagai Third Places bagi warga Tebet, karena memiliki citra Kawasan sebagai tempat "nongkrong" anak muda Jakarta yang kuat. Dengan banyaknya sekolah-sekolah yang ada di daerah Tebet, juga merupakan alasan Tebet menjadi salah satu tempat nongkrong Anak Muda di Jakarta.

Dengan demikian, mempertahankan Citra Kawasan merupakan suatu hal yang menjadi upaya bagi masyarakat setempat dimanapun untuk menjaga nilai-nilai yang menjadi ciri khas tempat tersebut. Dengan mengembahkan suatu public space yang menerapkan konsep baru yang memiliki fleksibilitas tinggi dan diharapkan menjadi wadah bersosialisasi baru bagi lingkungan sekitar dan juga mampu menambah nilai bagi kegiatan yang sudah ada lingkungan Tebet Timur itu sendiri. Re-Spot, Tebet : Spot Rekreasi Berbasis Olahraga di Tebet, hadir sebagai wadah rekreasi berbasis Olahraga berupa public space yang dapat dijadikan sebagai area meeting point dan berkegiatan olahraga bagi masyarakat dan menerapkan program baru yang menunjang kebutuhan dari Anak Muda di Tebet. Re-Spot tercipta dengan mempelajari kelebihan dan kekurangan pada daerah Tebet Timur itu sendiri.

\section{Latar Belakang Masalah}

Tebet yang dikenal sebagai salah satu tempat nongkrong favorite anak muda Jakarta dan juga tebet dikenal dengan sebutan surganya distro di Jakarta. Banyaknya spot untuk memenuhi kebutuhan Anak muda, hingga kini Tebet masih menjadi tujuan untuk para sebagian anak muda di Jakarta. Kurangnya spot hiburan/rekreasi yang bersifat "netral" menciptakan pergerakan pengunjung yang terjadi di Tebet menjadi cepat. Alur pengunjung yang terjadi kian menjadi cepat, karena sebagian pengunjung yang datang sudah memiliki tujuan yang spesifik ke suatu tempat di Tebet, yang kemudian setelahnya langsung meninggalkan tempat tersebut. Hal ini kian lama mampu mengurangi citra dari Kawasan Tebet itu sendiri, yang dikenal sebagai tempat nongkrong favorite Anak Muda Jakarta. Adapun public space di Tebet, namun waktu akses pengunjung cukup terbatas.

\section{Rumusan Permasalahan}

Fokus utama permasalahan dalam perencanaan dan perancangan yang diangkat pada proyek ini antara lain:

a. Bagaimana menciptakan Wadah Rekreasi berbasis Olahraga di Tebet sesuai dengan kriteria Third Place. 
b. Melihat kurangnya sarana Entertainment di Tebet, sehingga bagaimana membentuk kegiatan entertainment yang sesuai dengan kebutuhan anak muda dan masyarakat di Tebet Timur.

c. Bagaimana menghasilkan program baru yang kontekstual dengan memenuhi kebutuhan Anak Muda di Tebet.

d. Siteplanning: bagaimana bangunan dapat saling terkoneksi dengan bangunan sekitar dengan memperhatikan kenyaman secara pencapaian maupun bukaan bangunan.

e. Building: bagaimana program dapat saling berhubungan dengan pemanfaatan bangunan sehingga fungsi dapat maksimal.

\section{Ruang Lingkup}

Peneliti memfokuskan kegiatan rekreasi berbasis olahraga yang sesuai dengan trend di kalangan anak muda Jakarta yang sesuai di wilayah Tebet.

\section{Tujuan}

a. Merancang Spot Rekreasi berbasis Olahraga bagi Remaja di Kelurahan Tebet Timur untuk dapat mewadahi aktivitas remaja ke dalam sebuah sarana rekreasi dan edukasi yang bersifat sosial, kultural, dan rekreatif bagi penggunanya.

b. Menjadi wadah yang memfasilitasi kegiatan olahraga rekreasi remaja, yang juga memberikan wadah bagi masyarakat Jakarta baik individual ataupun komunitas.

c. Membuat konsep perencanaan dan perancangan dengan menekankan pendekatan arsitektur kontemporer dan mengangkat kebudayaan local agar dapat memperluas wawasan dan memacu semangat remaja dalam berkreasi dan berkegiatan khususnya olahraga.

\section{Kajian Literatur}

\section{Third Places}

Third places merupakan tempat yang mempertemukan berbagai macam masyarakat, dimana kegiatannya TIDAK terkait dengan rutinitas rumah (1st place) dan rutinitas pekerjaan (2nd place) (Winata, Open Architecture As..., 2020). Third places diperlukan bagi semua orang karena merupakan tempat dimana orang dapat melepaskan kepenatan yang terjadi pada aktivitas keseharian mereka. Maka pengertian dari Third places adalah suatu tempat yang memungkinkan seseorang untuk bersantai dan merasa terhibur untuk mengurangi rasa jenuh.

Menurut (Oldenburg, 1999) terdapat 8 karakter yang membentuk third place yaitu :

a. On Neutral Ground, Third places adalah alasan netral di mana individu bebas untuk datang dan pergi. (Quandt, 2014)

b. Leveler, Third places tidak mementingkan status individu dalam suatu masyarakat. Status ekonomi atau sosial seseorang tidak penting di tempat ketiga, memungkinkan rasa kesamaan di antara penghuninya. Tidak ada prasyarat atau persyaratan yang akan mencegah penerimaan atau partisipasi di tempat ketiga. (Wikipedia, 2019)

c. Conversation Is The Main Activity, brolan menyenangkan dan bahagia adalah fokus utama dari aktivitas di tempat ketiga, meskipun tidak harus menjadi satu-satunya aktivitas. (Wikipedia, 2019)

d. Accessibility And Accommodation, Third places harus mudah diakses bagi pengguna. (Quandt, 2014)

e. The Regulars, memiliki sejumlah pengunjung tetap yang membantu mengatur suasana tempat dan karakteristik daerah. Selain itu juga mampu menarik pendatang baru. (Wikipedia, 2019) 
f. Low Profile, Third place secara khas memiliki kesan sederhana dan tanpa tuntutan. (Quandt, 2014)

g. Mood Is Playful, Third place memiliki sifat yang menyenangkan, di mana percakapan cerdas dan olok-olok sembrono tidak hanya umum, tetapi sangat dihargai. (Wikipedia, 2019)

h. A Home Away From Home, Third place adalah seperti di rumah dalam hal perasaan memiliki, regenerasi spiritual, perasaan yang mudah dan hangat. (Quandt, 2014)

\section{Spot Rekreasi Berbasis Olahraga}

a. Spot : Menurut Cambridge Dictionary Spot adalah a place where an event is happening or has recently happened.

b. Rekreasi : Rekreasi adalah semua kegiatan yang dilakukan pada waktu senggang baik secara individual maupun secara bersama yang bersifat bebas dan menyenangkan, sehingga orang cenderung untuk melakukannya (Fairchild, 1994). Rekreasi meliputi pertandingan olahraga, santai, dan hobi. Rekreasi merupakan suatu kegiatan khusus yang ditentukan oleh elemen waktu, kondisi dan sikap seseorang dan lingkungannya. ${ }^{1}$

c. Olahraga : Olahraga merupakan salah satu bentuk aktivitas fisik yang sudah merupakan suatu bagian dari kegiatan hidup manusia (Aldiani, 2018). Menurut Kamus Besar Bahasa Indonesia, olahraga dapat diartikan sebagai gerak badan untuk menguatkan dan menyehatkan tubuh. Olahraga merupakan kebutuhan yang menjadi kebutuhan hidup untuk menjaga kesehatan, perkembangan jasmani, dan sosial.

d. Olahraga Rekreasi : Olahraga rekreasi adalah kegiatan fisik yang dilakukan pada waktu senggang berdsarkan keingginan atau kehendak yang timbul karena memberi kepuasan atau kesenangan (Haryono, 1988, p. 10). ${ }^{2}$ Ini terdiri dari olahraga setelah bekerja, pada akhir pekan, dalam liburan, dalam pensiun, atau selama periode (malang) pengangguran (Hagg, 1994). ${ }^{3}$

\section{METODE}

Metode perancangan yang digunakan yaitu Architectural Programming. Architectural Programming mendefinisikan masalah yang harus dipecahkan oleh upaya desain fisik. Architectural Programming menentukan apa yang harus dicapai sebelum Anda mulai mencapainya (Cherry, 1999). Langkah-langkah yang digunakan dalam metode Architectural Programming: (Cherry, 1999)

a. Latar belakang proyek penelitian (kunjungan situs, pencarian literatur)

b. Identifikasi sasaran dan sasaran

c. Kumpulkan informasi yang dianalisis

d. Pilih strategi untuk mencapai tujuan dan sasaran

e. Menetapkan persyaratan kuantitatif

f. Sintesis masalah desain

Dengan memperlajari trend olahraga tahun 2020 dan dengan peninjauan langsung terhadap lokasi yaitu kegiatan olahraga yang paling memiliki keterkaitan antara trend, Anak muda, dan Lingkungan.

\footnotetext{
${ }^{1}$ Hendra Kurniawan, 2013, Taman Rekreasi Air Di Pontianak, Kalimantan Barat, UAJY Repository, Hal. 10.

2 David Ben Gurion, 2014, Pusat Olahraga Rekreasi Futsal Di Sleman, Yogyakarta, Hal. 16. Universitas Atma Jaya Yogyakarta.

${ }^{3}$ Yanudya Ragil Widyaputra, 2019, Dampak Olahraga Rekreasi Pendakian Gunung, DIGILIB UNNES, 12.
} 


\section{DISKUSI DAN HASIL}

\section{Penjelasan Proyek}

Re-Spot, Tebet : Spot Rekreasi Berbasis Olahraga di Tebet merupakan duplikasi dari spot-spot nongkrong yang sudah ada sebelumnya di daerah Tebet, dan menjadi pilihan masyarakat untuk nongkrong dengan adanya injection program baru di dalamnya. Melihat kurangnya entertainment di Tebet, proyek ini mengembangkan Sport as Entertainment, dimana kegiatan entertainment disini merupakan bagian dari olahraga. Re-Spot mengkombinasikan kegiatan recreation, shopping, sport as entertainment, dan Support activity yang diharapkan dapat memberikan inovasi spot nongkrong bagi lingkungan Tebet Timur, dan juga menjadi ruang publik yang dapat menambah nilai bagi kegiatan yang sudah ada lingkungan Tebet Timur itu sendiri.

\section{Visi}

Merancang Spot Rekreasi berbasis Olahraga bagi Remaja di Kelurahan Tebet Timur untuk dapat mewadahi aktivitas remaja ke dalam sebuah sarana rekreasi dan edukasi yang bersifat sosial, kultural, dan rekreatif bagi penggunanya

\section{Misi}

a. Mengkaji potensi tapak dengan mengumpulkan data mengenai potensi lingkungan sekitar, kegiatan di sekitar lingkungan, dan fasilitas publik yang sudah ada di Tebet.

b. Menganalisis permasalahan proyek dan kebutuhan sesuai standar.

c. Mengolah tata ruang luar melalui pengolahan orientasi bangunan, lingkungan, material, dan fasad sesuai dengan standar perencanaan.

d. Mengolah tata ruang dalam melalui pendekatan tata cahaya, tata udara, bukaan, sirkulasi ruang, tekstur, dan material ruang dalam yang sesuai dengan konsep design by sports movement.

\section{Programmatik}

Selain mempertahankan citra daerah yang sebagai tempat "nongkrong" anak muda, tempat ini juga disiapkan untuk menjadi sarana bagi beberapa kegiatan olahraga. Pada proyek ini, akan melakukan pendekatan pada Third Places, Health, Fitness and the Environment.

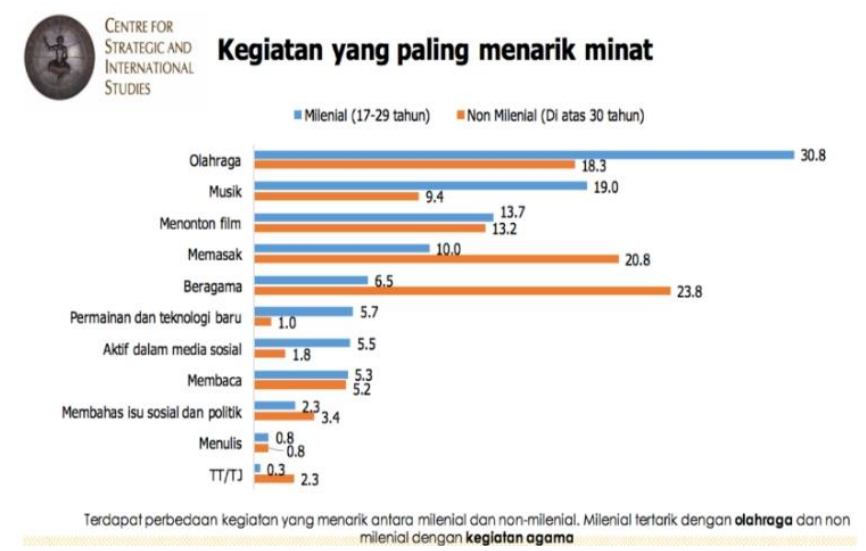

Gambar 1. Survei Kegiatan Yang Paling Menarik Minat Milenial dan Non Milenial Sumber : (Centre for Strategic and International Studies, 2017) 


\section{AKTIVITAS YANG PALING DISUKAI MILLENNIAL (\%)}

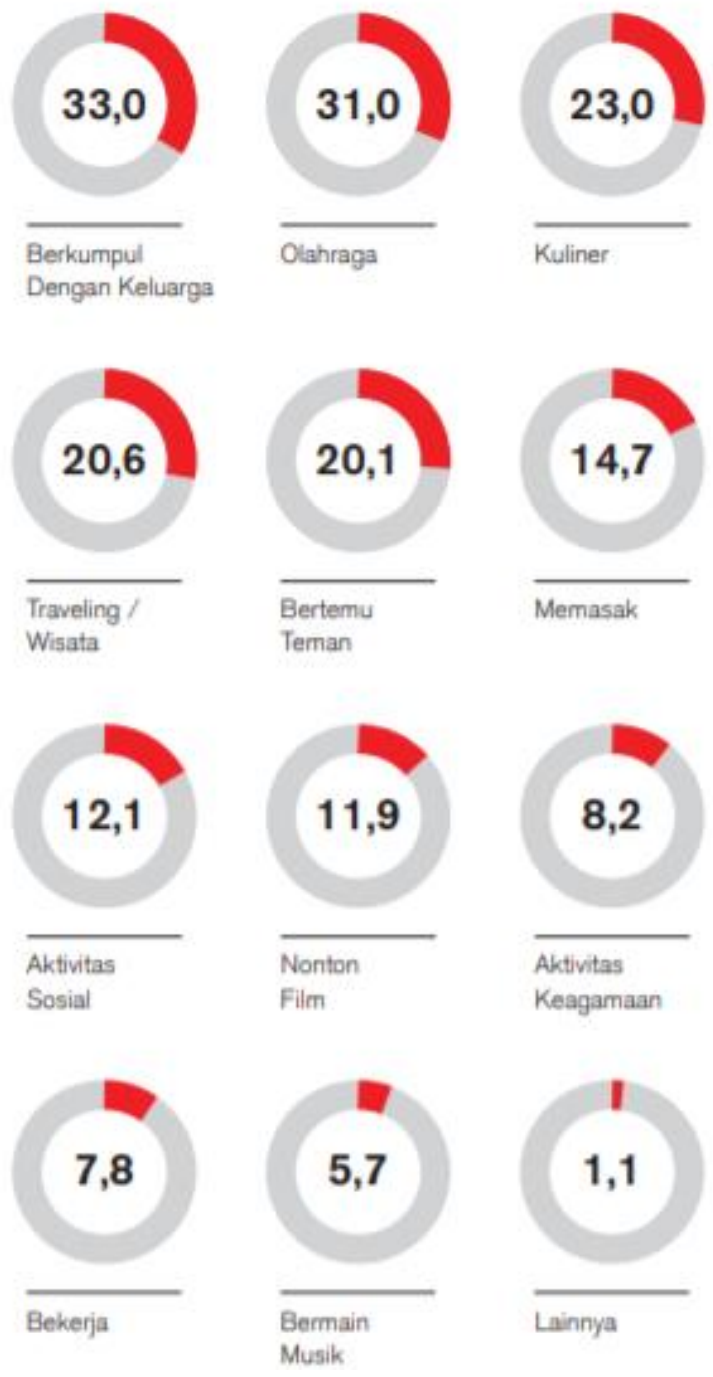

Gambar 2. Diagram Aktivitas yang paling disukai Milenial

Sumber : (Utomo, 2019)

Kedua hasil survei diatas menunjukkan bahwa generasi millennial memiliki minat yang dominan pada olahraga. Namun pada survei kedua terdapat kegiatan lain yaitu berkumpul dengan keluarga. Karena daerah ini memiliki karakteristik tempat berkumpulnya anak muda dimana usia remaja umumnya sekitar 14-22 tahun. Sehingga sangat berpotensi untuk menciptakan suatu wadah yang dapat dimanfaatkan sebagai sarana olahraga. Pemilihan program Olahraga didasari dari survei minat Anak muda dan trend olahraga yang diminati oleh masyarakat. Program yang berbasis masyarakat dapat menggunakan hasil survei ini untuk mendapatkan kesesuaian program olahraga yang kemungkinan besar dapat berkembang yang mampu melayani keluarga dan anak-anak. Dan juga suatu Klub kesehatan komersial dapat menggunakan hasil ini untuk membangun (atau mungkin pembenaran) potensi pasar baru, yang dapat menghasilkan peningkatan dan pendorong pendapatan yang lebih berkelanjutan (Thompson, 2019). 
Tabel 1. Data Trend Olahraga Dunia 3 tahun terakhir

\begin{tabular}{|c|c|c|}
\hline 2018 & 2019 & 2020 \\
\hline $\begin{array}{l}\text { 1. High Intensity Interval } \\
\text { Training (HIIT) }\end{array}$ & 1. Wearable Technology & 1. Wearable Technology \\
\hline 2. Group Training & 2. Group Training & $\begin{array}{l}\text { 2. High Intensity Interval } \\
\text { Training (HIIT) }\end{array}$ \\
\hline 3. Wearable technology & $\begin{array}{l}\text { 3. High Intensity Interval Training } \\
\text { (HIIT) }\end{array}$ & 3. Group Training \\
\hline 4. Body weight training & $\begin{array}{l}\text { 4. Fitness Programs for Older } \\
\text { Adults }\end{array}$ & 4. Training with Free Weights \\
\hline 5. Strength Training & 5. Body Weight Training & 5. Personal Training \\
\hline $\begin{array}{l}\text { 6. Educated, Certified and } \\
\text { Experienced Fitness } \\
\text { Professionals }\end{array}$ & $\begin{array}{l}\text { 6. Employing Certified Fitness } \\
\text { Professionals }\end{array}$ & 6. Exercise is Medicine (EIM) \\
\hline 7. Yoga & 7. Yoga & 7. Body Weight Training \\
\hline 8. Personal Training & 8. Personal Training & $\begin{array}{l}\text { 8. Fitness Programs for Older } \\
\text { Adults }\end{array}$ \\
\hline $\begin{array}{l}\text { 9. Fitness Programs for Older } \\
\text { Adults }\end{array}$ & 9. Functional Fitness Training & 9. Health/Wellness Coaching \\
\hline 10. Functional Fitness & 10. Exercise is Medicine & $\begin{array}{l}\text { 10. Employing Certified } \\
\text { Fitness Professionals }\end{array}$ \\
\hline
\end{tabular}

Sumber : (Thompson, 2019)

Tentu apa yang menjadi tren di Dunia belum tentu akan berpengaruh pada tren di Indonesia, tapi tidak menutup kemungkinan juga untuk menjadi tren Olahraga di Indonesia.

Tabel 2. Perbandingan tren olahraga di Dunia menurut (Thompson, 2019) dan di Indonesia menurut (Wisnubrata, 2020)

\begin{tabular}{|c|c|}
\hline \multicolumn{2}{|c|}{ Prediksi Tren Olahraga 2020 } \\
\hline Dunia & Indonesia \\
\hline Wearable Technology & Strength training \\
\hline High Intensity Interval Training & Lari \\
\hline Group Training & Skateboarding \\
\hline Training with Free Weights & HIIT / HILIT (High Intensity Low \\
Impact Training)
\end{tabular}

Sumber : Dokumen pribadi, 2020 


\section{Sport As Entertainment}

Merupakan program olahraga rekreasi yang berupa hasil analisis program melalui riset trend 2020 dan kebutuhan lingkungan sekitar Tebet Timur yang juga bagian dari injection program yaitu dengan mengelaborasikan kegiatan olahraga dengan kegiatan hiburan yang sedang berkembang. Sehingga kegiatan hiburan yang diciptakan merupakan bagian dari olahraga.

Kebutuhan ruang Olahraga Rekreasi: Sport plaza, lapangan bulu tangkis, ruang ganti, dan area penunjang.

\section{Injection Program}

a. Roller Disco

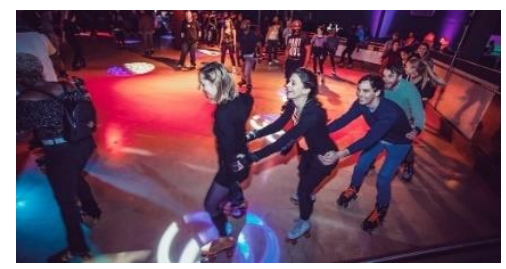

Gambar 3. Roller Disco

Sumber : (google, 2020)

Roller disco adalah sebuah tren aktivitas remaja dimana semua penari memakai sepatu roda. Musik yang dimainkan adalah music modern. Konsep ini muncul sebagai tren di tahun 1970-an. Pada tahun 1984, tren tersebut tiba di Inggris dan banyak diskotik bermunculan di seluruh negeri (Wikipedia, 2019). Tren ini kembali dimunculkan pada salah satu tempat di daerah Pondok Indah, MoJa Museum. Hingga saat ini, roller skating dijadikan hobi atau aktivitas olahraga oleh sebagian orang.

\section{b. Trampoline}

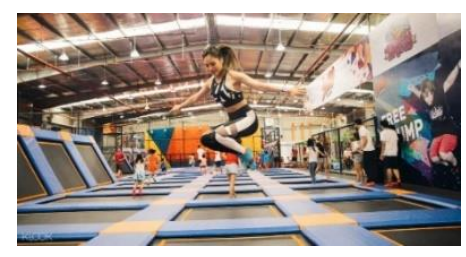

Gambar 4. Trampoline

Sumber : (google, 2020)

Trampoline adalah salah satu alat yang biasa digunakan anak-anak maupun orang dewasa untuk bermain lompat-lompatan. Melompat dengan trampolin berfungsi sebagai latihan kardiovaskular yang sangat baik dengan meningkatkan denyut jantung dan menjaganya agar tetap sehat. (Niken Anggun Nurani, 2013)

\section{c. Virtual Reality Games}

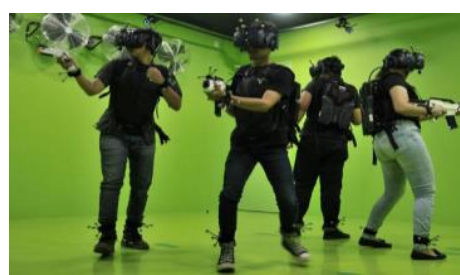

Gambar 5. VR Game

Sumber : (google, 2020) 
Keunggulan olahraga ini adalah pengguna merasa bersemangat tidak terlalu capai karena terdistraksi dengan permainan (Firdaus Anwar, 2019). "Olahraga dengan VR sangat, sangat baik mendistraksi kenyataan bahwa kamu sedang berolahraga dan membuat kamu hanya menikmati permainan saja," kata Aaron seperti dikutip dari CNN, Senin (21/1/2019) (Firdaus Anwar, 2019).

\section{Recreation}

Merupakan program berfungsi untuk mewadahi kegiatan nongkrong di Tebet, yang menjadi spot rekreasi yang bersifat Fleksibel dan netral bagi penggunanya. Program ini juga bertujuan untuk memperkuat konsep dari Kawasan Tebet ini sendiri. Kegiatannya diantara lain nongkrong, bersantai, nonton bareng, makan-minum, dan bermain. Sehingga menciptakan area yang playfull.

Kebutuhan ruang: Seating Area, area nonton, slide area, net floor area, dan area penunjang.

\section{Shopping}

Merupakan program untuk memenuhi kebutuhan lahan untuk pengusaha dibidang retail. Khususnya untuk mengembangkan Distro di daerah Tebet, yang mana sudah menjadi citra Kawasan Tebet itu sendiri yaitu sebagai pusat distro di Jakarta. Kebutuhan ruang: Area retail, ruang penyimpanan, dan area penunjang

\section{Tapak}

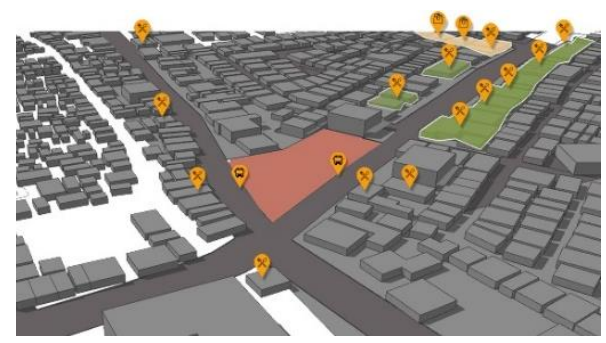

Gambar 6. Lokasi Tapak Terpilih

Sumber : Dokumen pribadi, 2020

Lokasi tapak terpilih adalah: Jl. Tebet Raya No.23, RT.1/RW.2, Tebet Tim., Kec. Tebet, Kota Jakarta Selatan, Daerah Khusus Ibukota Jakarta 12820. Karena telah memenuhi kriteria yang mengacu pada karakteristik third places menurut teori, yaitu :

a. Akses mudah, karena berada di perbatasan Kelurahan Tebet Timur sehingga memudahkan akses tidak hanya untuk warga Tebet Timur. Tapak juga berada di jalur yang dilalui kendaraan saat melintasi daerah Tebet Timur.

b. Disekitar tapak memiliki perbedaan tingkat keramaian yang cukup signifikan.

c. Dekat dengan permukiman, agar program dapat memfasilitasi kebutuhan olahraga warga sekitar dan sebagai tempat meeting point di setiap harinya.

\section{Proses Pembentukan Massa}
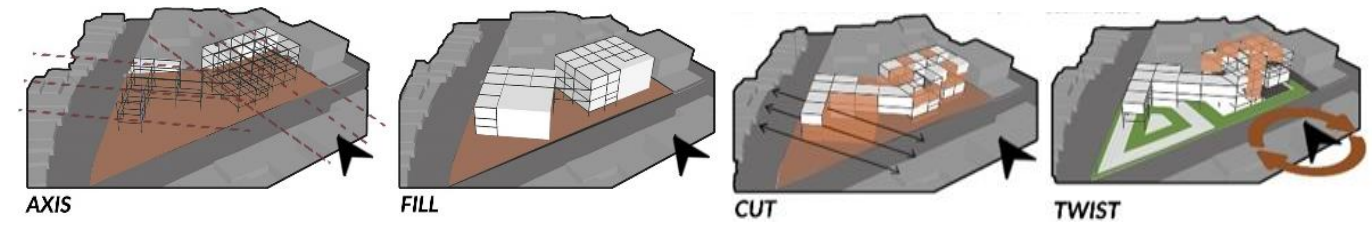

Gambar 7. Proses Pembentukan Massa

Sumber : Dokumen Pribadi,2020 
Proses pembentukan massa menggunakan pendekatan dengan memperhatikan lingkungan sekitar tapak agar menghasilkan gubahan massa yang kontekstual lingkunan sekitarnya.

\section{Konsep Sirkulasi Bangunan}

Design by Sport Movement merupakan konsep desain pada dalam bangunan, yaitu sirkulasi yang diciptakan sebagaimana gerakan dari olahraga dengan mempertimbangkan aspek kenyamanan pengguna sesuai ergonomi.

a. Step-Lift

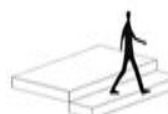

Gambar 8. Diagram gerak Step-Lift

Sumber : Dokumen pribadi, 2020

Sirkulasi dalam bangunan maupun di luar bangunan dibuat adanya perbedaan peil lantai sehingga membutuhkan step-step tangga.

b. Squat-Sit

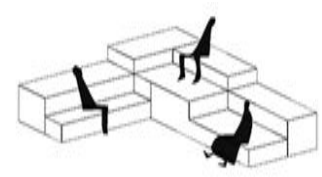

Gambar 9. Diagram gerak Squat-Sit

Sumber : Dokumen pribadi, 2020

Area istirahat atau nongkrong dibuat fleksible dengan memungkinkan pengguna bercengkrama ataupun istirahat senyaman mungkin sesuai standar ergonomi.

c. Climb-Crawl

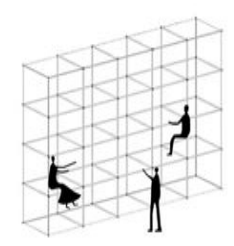

Gambar 10. Diagram gerak Climb-Crawl

Sumber : Dokumen pribadi, 2020

Terdapat area wall climbing yang mewakili sport recreation, dan terdapat perbedaan rangka yang memungkinkan untuk hanging.

d. Bounce - Jump -Lay

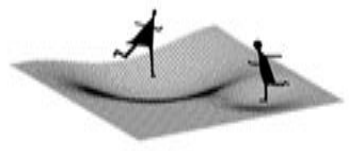

Gambar 11. Diagram gerak Climb-Crawl

Sumber : Dokumen pribadi, 2020 
Terdapat sirkulasi yang dilalui pengguna dengan menggunakan net dimana membutuhkan keseimbangan pengguna yang melaluinya.

\section{Hasil Perancangan}

Tabel 3. Hasil Perbandingan Perancangan dengan Indikator

\begin{tabular}{|c|c|}
\hline INDIKATOR & RE-SPOT, TEBET \\
\hline $\begin{array}{l}\text { a. On Neutral Ground, } \\
\text { Tempat yang memiliki sifat Netral } \\
\text { dimana tidak ada kewajiban yang mutlak } \\
\text { untuk berasa disana. Dan juga tidak } \\
\text { memiliki keterikatan baik secara } \\
\text { finansial, politik, hukum dan sebagainya. }\end{array}$ & $\begin{array}{l}\text { Memiliki Open Area yang dimana mampu } \\
\text { mewadahi pengguna dengan berbagai kegiatan } \\
\text { yang bersifat fleksibel. Sehingga tidak memiliki } \\
\text { kegiatan yang spesifik. }\end{array}$ \\
\hline $\begin{array}{l}\text { b. Leveler, } \\
\text { Ruang Ketiga tidak mementingkan status } \\
\text { bagi penggunanya. Baik status ekonomi } \\
\text { maupun sosial seseorang. }\end{array}$ & $\begin{array}{l}\text { Re-Spot, Tebet yang ditujukan untuk menunjang } \\
\text { kebutuhan remaja di Tebet yaitu "nongkrong," } \\
\text { dimana kegiatan tersebut merupakan kegiatan } \\
\text { umum yang dapat dilakukan bagi setiap lapisan } \\
\text { masyarakat. }\end{array}$ \\
\hline $\begin{array}{l}\text { c. Conversation Is The Main Activity, } \\
\text { Kegiatan yang diutamakan yaitu kontak } \\
\text { sosial secara langsung seperti } \\
\text { mengobrol, meskipun hal tersebut tidak } \\
\text { harus menjadi satu-satunya aktivitas } \\
\text { pada suatu Ruang Ketiga. }\end{array}$ & $\begin{array}{l}\text { Re-Spot, Tebet mengutamakan menyediakan } \\
\text { spot-spot nongkrong bagi penggunanya, dimana } \\
\text { yang memiliki tujuan untuk menciptakan tempat } \\
\text { yang nyaman untuk melakukan interaksi sosial } \\
\text { antar pengguna. }\end{array}$ \\
\hline $\begin{array}{l}\text { d. Accessibility And Accommodation, } \\
\text { Ruang ketiga harus mudah diakses bagi } \\
\text { pengguna dan bersifat terbuka. Dan juga } \\
\text { bersifat akomodatif yang artinya mampu } \\
\text { memenuhi kebutuhan penggunanya. }\end{array}$ & $\begin{array}{l}\text { Pemilihan tapak juga merupakan bagian dasar } \\
\text { dalam menentukan kemudahan akses bagi } \\
\text { penggunannya. Dan juga akses bagi pejalan kaki } \\
\text { dan pengguna kendaraan umum diutamakan. }\end{array}$ \\
\hline $\begin{array}{l}\text { e. The Regulars, } \\
\text { Ruang Ketiga memiliki pengguna tetap } \\
\text { yang dapat selalu beraktivitas di dalam } \\
\text { sebuah Ruang Ketiga. Namun juga } \\
\text { Ruang Ketiga harus mampu menarik } \\
\text { pendatang baru dan bersifat terbuka } \\
\text { untuk setiap pendatang baru. }\end{array}$ & $\begin{array}{l}\text { kegiatan olahraga badminton ini cukup menjadi } \\
\text { kegemaran masyarakat Tebet sehingga mampu } \\
\text { menjadi aktivitas rutin yang memnuhi kebutuhan }\end{array}$ \\
\hline
\end{tabular}




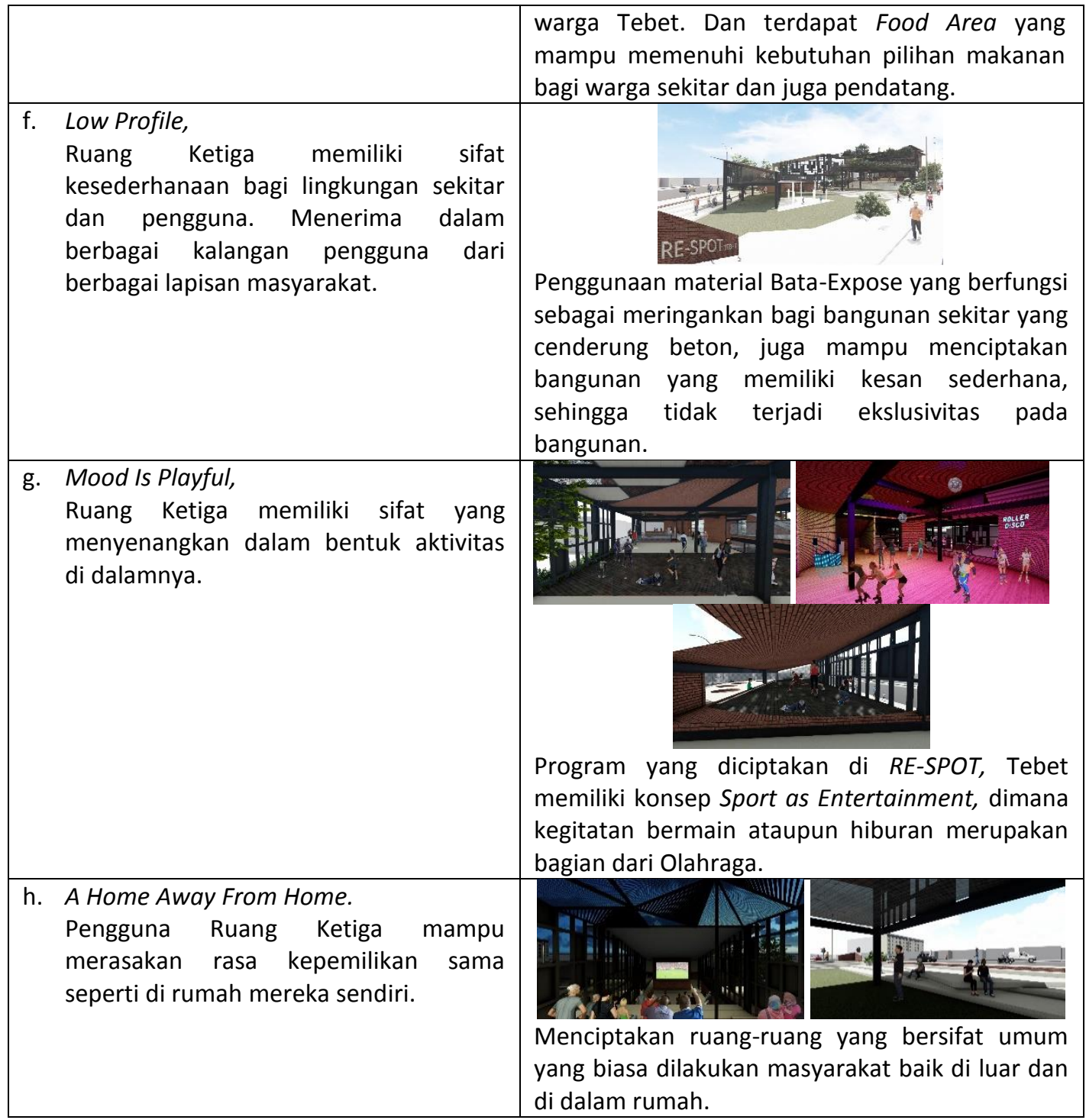

Sumber : Dokumen Pribadi, 2020

Hasil

a. Re-Spot mampu bersifat netral karena memiliki Open Area yang dimana mampu mewadahi pengguna dengan berbagai kegiatan yang bersifat fleksibel. Sehingga tidak memiliki kegiatan yang spesifik.

b. Re-Spot, mampu bersifat leveler karena fokus pada menunjang kebutuhan "nongkrong" dimana kegiatan tersebut merupakan kegiatan umum yang dapat dilakukan bagi setiap lapisan masyarakat.

c. Kegiatan "nongkrong" di Tebet yang merupakan salah satu fokus kegiatan perancangan pada Re-Spot memiliki tujuan untuk menciptakan tempat yang nyaman untuk melakukan interaksi sosial antar pengguna.

d. Re-Spot mengutamakan akses bagi pejalan kaki dan pengguna kendaraan umum.

e. Mampu memiliki pengguna tetap karena terdapat program yang disesuaikan dengan kebutuhan warga dan lingkungan sekitar sehingga dapat digunakan untuk kegiatan seharihari yang juga berpotensi menarik minat pendatang. 
f. Penggunaan material Bata-Expose mampu menciptakan bangunan yang memiliki kesan sederhana, sehingga tidak terjadi ekslusivitas pada bangunan.

g. Program yang diciptakan di Re-Spot memiliki konsep Sport as Entertainment, dimana kegitatan bermain ataupun hiburan merupakan bagian dari Olahraga. Sehingga sebagian besar aktivitas cenderung bermain.

h. Re-Spot menciptakan ruang-ruang yang bersifat umum yang biasa dilakukan masyarakat baik di luar dan di dalam rumah.

\section{KESIMPULAN DAN SARAN}

\section{Kesimpulan}

Perancangan proyek ini memiliki tujuan untuk dapat mewadahi aktivitas remaja di Tebet dalam sebuah sarana rekreasi yang bersifat sosial, dan rekreatif bagi penggunanya, dan mampu memfasilitasi kegiatan olahraga rekreasi remaja guna memberikan semangat kepada masyarakat dalam berolahraga. Re-Spot, Tebet : Spot Rekreasi Berbasis Olahraga di Tebet merupakan duplikasi dari Spot-Spot nongkrong di daerah Tebet, dan dengan adanya Injection Program baru di dalamnya. Dengan melihat kurangnya jenis fasilitas hiburan di Tebet, proyek ini mengembangkan Sport as Entertainment, dimana kegiatan entertainment disini merupakan bagian dari olahraga. Re-Spot mengkombinasikan kegiatan recreation, shopping, Sport as Entertainment, dan Support activity yang diharapkan dapat memberikan inovasi Spot nongkrong bagi lingkungan Tebet Timur, dan juga menjadi ruang publik yang dapat menambah nilai bagi kegiatan yang sudah ada lingkungan Tebet Timur. Proyek ini menghadirkan Injection Program baru yang berupa hasil analisis program melalui riset trend dan kebutuhan lingkungkan sekitar Tebet Timur yang dielaborasikan dengan kegiatan entertainment yang sedang berkembang. Jadi dalam penelitian ini, penulis menemukan bahwa sebuah Ruang Ketiga untuk masyarakat di suatu daerah harus mampu memperkuat atau mempertahankan karakteristik daerah tersebut agar mampu menjadi Ruang Ketiga dengan pemanfaatan bangunan yang maksimal dan ramah bagi penggunanya khususnya bagi warga sekitar.

\section{Saran}

Dari beberapa kesimpulan yang diperoleh dalam proses penyusunan Jurnal dengan judul "ReSpot : Spot Rekreasi Berbasis Olahraga di Tebet" yang telah dijabarkan sebelumnya, maka penulis memberikan saran dan masukan untuk pengembangan dalam perancangan yang lebih lanjut. Saran dan tersebut terkait dengan konsep yang diajukan dalam pembentukan Spot nongkrong anak muda di Jakarta untuk diterapkan lebih kuat dengan pertimbangan karakteristik lingkungan di sekitar tapak, sehingga mampu menambah nilai bagi kegiatan yang sudah ada lingkungan itu sendiri. Studi literatur diharapkan lebih sering dilakukan untuk memperoleh referensi desain yang akan dihasilkan, sehingga mampu lebih kreatif dan inovatif.

\section{REFERENSI}

Aldiani, R. C. (2018). Analisis Paparan Informasi Ajakan Berolahraga Terhadap Pengetahuan, Gaya Hidup, dan Intensi Perilaku Olahraga Pada Mahasiswa.

Centre for Strategic and International Studies. (2017). Laporan Survei Nasional Milenial. Jakarta: Centre for Strategic and International Studies.

Edith Cherry, F. (1999). Programming for Design. Canada: John Wiley \& Sons, Inc.

Fairchild, H. P. (1994). Dictionary of Sociology. New York: Philosophical Library.

Firdaus Anwar. (2019, January 21). Retrieved from Detik Health: https://health.detik.com

Google. (2020). Retrieved from google: https://www.google.com 
Gurion, D. (2014). Pusat Olahraga Rekreasi Futsal Di Sleman. Yogyakarta: Universitas Atma Jaya Yogyakarta.

Hagg, H. (1994). Sport pedagogy. Michigan: Human Kinetics.

Haryono, W. (1988). Pariwisata Rekreasi dan Entertainment. Bandung: ILMU Publishers.

Kurniawan, H. (2013). Taman Rekreasi Air Di Pontianak, Kalimantan Barat. UAJY Repository, 10.

Niken Anggun Nurani. (2013, Januari 22). Retrieved from Okelifestyle: https://lifestyle.okezone.com

Oldenburg, R. (1999). The Great Good Place. Cambridge: Da Capo Press.

Purwantiasning, A. W. (2017). Optimalisasi Fungsi Ruang Terbuka Hijau Dengan Melihat Pola Sebaran Pengunjung. National Academic Journal of Architecture, 121-127.

Quandt, T. (2014). Multiplayer: The Social Aspects of Digital Gaming. New York: Routledge.

Thompson, W. R. (2019). Worldwide Survey Of Fitness Trends For 2020. ACSM's Health \& Fitness Journal, 10-18.

Utomo, W. P. (2019). Indonesia Millennial Report. IDN Research Institute.

Widyaputra, Y. R. (2019). Dampak Olahraga Rekreasi Pendakian Gunung. DIGILIB UNNES, 12.

Wikipedia. (2019, April 12). Retrieved from Wikipedia: https://en.wikipedia.org

Winata, S. (2020, January 12). Open Architecture As... (S. Winata, Performer) Jakarta Barat, DKI Jakarta, Indonesia

Winata, S. (2020). Pedoman Mata Kuliah STUPA 8.29. Jakarta : Jurusan Arsitektur Universitas Tarumanagara.

Wisnubrata. (2020, January 30). Home/Lifestyle/Feel Good. Retrieved from Kompas.com: https://lifestyle.kompas.com 